\title{
Review
}

\section{Towards safer vectors for the field release of recombinant bacteria}

\author{
John DAVISON \\ Laboratoire de Biologie Cellulaire, Institut National de la Recherche Agronomique, INRA-Versailles, 78026 Versailles Cedex, France
}

The prospect of the deliberate environmental release of genetically manipulated microorganisms has given rise to a great deal of polemic. Amongst the rational scientific concerns are those concerned with the fate of the released bacteria, the fate of the recombinant genes that they carry, the selective pressures acting upon them in different environmental situations and the long term effects on the environment and human health. All recombinant DNA is carried by vectors (plasmids, transposons or bacteriophage or remnants of these). Thus the way in which recombinant constructions are made may itself lead to potential biosafety concerns, irrespective of the host bacterium and the recombinant DNA fragment of primary interest. The purpose of the present review is to assess progress in improved vector design aimed at eliminating risks due to the way recombinant vectors are constructed. Improved vector constructions include the avoidance of the use, or removal, of antibiotic resistance genes, the use of defective transposons rather than plasmids in order to reduce horizontal transfer and the development of conditionally lethal suicide systems. More recently, new site-specific recombination systems have permitted transposon vectors to be manipulated following strain construction, but before environmental release, so that virtually all recombinant DNA not directly involved in the release experiment is eliminated. Such bacteria are thus pseudo-wild type in that they contain no heterologous DNA other than the genes of interest.

Key words: recombinant DNA, horizontal gene transfer, plasmid, transposon, vector, biological control, suicide genes, biodegradation, site-specific recombination, GMO.

Recombinant DNA technology has resulted in dramatic advances in biotechnology and medicine and has potential environmental applications in biocontrol (Haas et al., 2000) and bioremediation (de Lorenzo, 1994; Pieper and Reineke, 2000), as well as in oral recombinant vaccines (Bumann et al., 2000). While our understanding of the basic science of these processes has made dramatic advances over the last 20 years, few field trials with recombinant microorganisms have been made (Sayler and Ripp, 2000). Indeed, legislation both in the USA (EPA Toxic Substances Control Act) and in Europe (EC Council Directives on the deliberate release into the environment of genetically modified organisms, 90/220, 2002/18) requires extensive strain documentation and environmental impact characterization that is not easily obtained (Dammann-Kalinowski et al., 1996; Miller, 1997; Ramos et al., 2000). One of the main reasons for this is that, while industrial recombinant bacteria (designed for example to produce pharmaceutical protein in a fermentor) can be adequately contained, bacteria designed for field application cannot. This has given rise to a variety of concerns (some scientific, some ethical, some rational, some illogical) over the safety or biohazard potential of the released microorganisms. These concerns and possible ways to evaluate them have been reviewed previously (Kappeli and Auberson, 1997). Potential biosafety issues can be divided into three major types.

The first type involves the potential risks associated with the release of the non-recombinant host bacterium and is independent of whether the microorganism is

Corresponding author:

Tel.: (33) 1308336 82; fax: (33) 1308337 28; e-mail: davisona@ jouy.inra.fr 


\section{J. Davison}

recombinant. For example, while all may have natural bioremediation and biocontrol capacities, it would be generally agreed that Pseudomonas putida, or $P$. fluorescens, poses a lesser risk than $P$. aeruginosa, or Burkholderia cepacia; these latter being implicated in human and animal disease (Govan et al., 1996; Holmes et al., 1998).

The second type involves the potential risks associated with the specific DNA fragment of interest to the recombinant DNA release experiment. For example, the toluene degradation genes of $P$. putida, or the nitrogen fixation genes of Sinorhizobium meliloti, should have a lower risk potential for human health than those of the virulence genes of, for example Vibrio cholerae. Problems of this type have no general solution and must be resolved on a case-by-case basis (Kappeli and Auberson, 1997).

The third type of potential risk, which is the only one that will be dealt with in this review, involves the way in which the recombinant DNA strain is constructed. Most types of recombinant constructs include antibiotic resistance genes, which act as selective markers after transformation. This methodology has been criticized on the grounds that it may contribute to the spread of antibiotic resistance and negatively impact on human health. Using modern gene technology, the use of such antibiotic resistance genes can be circumvented, either by replacing them by more environmentally-friendly genetic markers or by removing them completely using site-specific recombination. This kind of preventive approach attempts to foresee potential biosafety problems with genetically engineered microbes, and to avoid them. It can also be applied to origins of replication, parts of plasmids, parts of transposons and a variety of other undesired and unnecessary pieces of DNA that were part of the original genetic constructions. Still other new microbial engineering tools are now available that eliminate unwanted genes, increase stability, reduce horizontal transfer and, under appropriate conditions, induce suicide of the host bacterium. Finally, though outside the scope of the present review, it should further be noted that similar site specific recombination methodology is now being used in plant genetic engineering to remove antibiotic, or herbicide, resistance genes and other unwanted DNA fragments (Zuo et al., 2002).

\section{VECTORS FOR ENVIRONMENTAL RELEASE}

\section{Plasmid vectors}

The construction of recombinant bacteria necessitates the use of vectors that are DNA molecules small enough to be isolated in pure form and experimentally manipulated. These vectors are self-replicating or are carried by selfreplicating molecules. For environmental purposes, vectors may be plasmids or transposons (these latter do not usually replicate and are often carried by plasmids). In addition, vectors inevitably carry selectable genetic markers that, historically, were usually antibiotic resistance genes. Objections have been raised against the use of plasmid vectors, since these may be horizontally transferred to other bacteria in the environment (Davison, 1999). Even when non-conjugative, non-mobilizable plasmids are used, these may still be transferred, in the presence of a conjugative plasmid, by co-integrate formation (plasmid fusion) catalyzed, for example, by a Tn3-type transposon (Top et al., 1990; Davison, 1999). In the case of most Gram-negative bacteria, broad hostrange plasmid vectors (such as RSF1010 or RK2), able to be mobilized and to replicate in most kinds of Gramnegative bacteria, are usually used; further complicating the problem of horizontal transfer to other species (Davison, 1999; Davison, 2002). Furthermore, bacteria containing recombinant plasmids, with few exceptions, are not suitable for environmental release experiments since their long-term stability depends on the maintenance of the selective pressure (usually an antibiotic), which cannot be easily accomplished in environmental situations.

\section{Transposon vectors}

In contrast to plasmids, the frequency of horizontal transfer of chromosomal markers is low, especially between unrelated species, where recombination frequency is drastically decreased by the mutSL mismatch repair system (Matic et al., 1996). For this reason, the tendency has been to use chromosomally integrated transposons as vectors for environmental release (Davison et al., 1990; Kaniga and Davison, 1991). Transposon vectors also have the advantage of stability in the absence of continued genetic selection. Recombinant transposons, carried by non-replicating plasmid suicide vectors that are rapidly eliminated following transposition, can be delivered to the host chromosome (Davison, 1999; Davison, 2002). However, transposons, by their very nature, are mobile genetic elements and it was further necessary to physically dissociate the transposon from its transposase gene, so that once transposition had taken place, the transposon could not re-transpose (de Lorenzo et al., 1990; Herrero et al., 1990; de Lorenzo and Timmis, 1994; de Lorenzo et al., 1998). These ideas are shown diagrammatically in 
A)

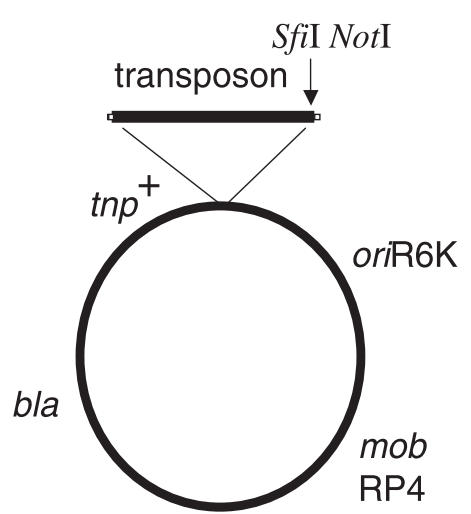

B)

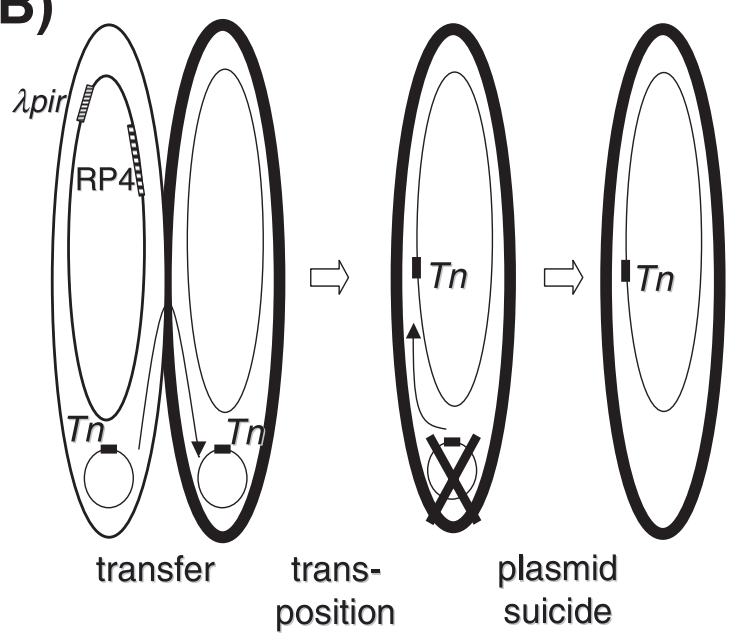

Figure 1. Transposition of a mini-transposon.

(A) The transposon delivery vehicle (circle) is an R6K-based host-specific plasmid, unable to replicate in most hosts since it lacks the gene (pir) coding for it's DNA replication. It contains an antibiotic marker such as bla for the resistance to ampicillin, and the mob genes of RP4, permitting mobilization in the presence of a conjugative plasmid such as RP4. It also contains the tnp gene coding for the transposase of the $T n 5$, that catalyses the transposition of the transposon. The $\operatorname{Tn} 5$ mini-transposon contains a selective gene (e.g. resistance to kanamycin) and the transposon ends necessary for transposition. It contains no other genes but has two sites for rare-cleavage restriction enzymes SfiI and NotI at which recombinant DNA may be inserted.

(B) The bacterium on the left (thin cell wall) is E. coli S171 (Apir) or some similar strain. It contains a chromosomally integrated RP4 plasmid (able to facilitate conjugation) and a $\lambda$ pir phage (able to complement the replication defect of the delivery plasmid). The transposon delivery vehicle shown in Figure $1 \mathrm{~A}$ is represented by the small circle. Mating with Pseudomonas (thick cell wall) results in plasmid transfer, but the plasmid is unable to replicate in Pseudomonas and is lost. The transposon is also lost, except on rare occasions when it transposes to the Pseudomonas chromosome, where it is stably maintained.
Figure 1, where the suicide plasmid carries a defective mini-transposon in which the transposase gene is located on the delivery plasmid replicon outside of the transposon. Thus, following transposition, the transposase gene is lost together with the suicide delivery plasmid. Furthermore, it is known that transposase functions very poorly in trans so that complementation by another similar transposon is unlikely. Thus the defective transposon is more or less permanently fixed in the chromosome of the recipient strain.

\section{Selective markers}

For environmental release experiments, the use of antibiotic resistance genes as selective markers has often been publicly criticized on the grounds that these resistance genes may be transferred from the released strain to pathogens. However, overuse and abuse of antibiotics has been common practice for many years (Davies, 1997; Barbosa and Levy, 2000; Hooton and Levy, 2001). Pathogens carrying highly transmissible plasmid-borne antibiotic resistance genes are already common in hospitals, intensive animal farms, and even in orchards and fish farms. It should also be remembered that the antibiotic resistance genes used in recombinant DNA constructs are themselves derived from antibiotic resistance plasmids isolated from medically important bacteria. Thus, the logic arguing for a major risk from genetically engineered sources may be overstated. Nonetheless, the question is easily avoided by the use of non-antibiotic resistance markers that are unlikely to negatively impact on human biosafety. Thus, new transposon vectors have been constructed that carry different, more environmentally friendly, selective markers such as resistance to the herbicide Bialaphos, to mercuric salts and organomercuric compounds, and to arsenite (Herrero et al., 1990; de Lorenzo and Timmis, 1994; de Lorenzo, 1994; Saint et al., 1995; de Lorenzo et al., 1998). More recently, new mini-transposons and plasmids have been constructed that use tellurite resistance as the selective marker (Sanchez-Romero et al., 1998). Similarly nickel resistance, encoded by the $n r e$ genes, has been incorporated into mini-transposons and shown to have a wide host-range of nickel resistance covering members of the $\alpha, \beta$, and $\gamma$ subclasses of the Proteobacteria (Taghavi et al., 2001). Siderophore receptors have also been used in $P$. putida, since these permit the selection of bacteria having the appropriate receptor in iron deficient conditions and in the presence of the siderophore (Raaijmakers et al., 1994). Other variants include transposons carrying genes for growth 
J. Davison

A)

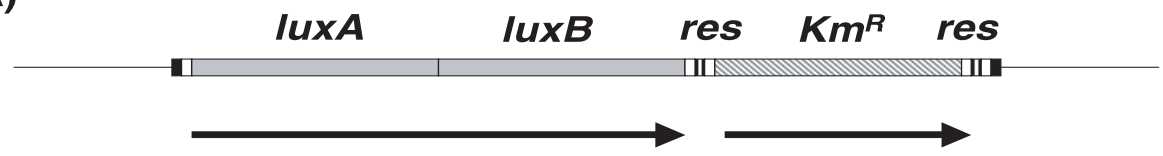

B)

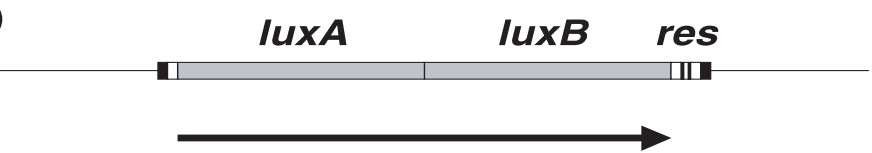

Figure 2. Elimination of unwanted genes by site specific recombination.

(A) Following the method described in Figure 1, a $T n 5$ mini-transposon, containing (for example) the $l u x A B$ genes and a selective marker $\mathrm{Km}^{R}$, has been integrated into the chromosome. The latter gene is flanked on either side by res sites.

(B) Transient expression of the site specific resolvase, carried by a non-replicating plasmid, results in excision of the DNA between the res sites, including the $K m^{R}$ gene, leaving the lux genes intact.

on particular carbon sources, such as lactose (Kok et al., 1994; Hansen et al., 1997) or toluene (Sanchez-Romero et al., 1998; Panke et al., 1998), though these markers are inconvenient due to the large size of the genetic information required. These alternative selective markers for transposon vectors are only required during the laboratory manipulations and would probably not be expected to confer any selective advantage under normal field conditions nor to pose human biosafety concerns.

\section{SITE-SPECIFIC REMOVAL OF UNWANTED DNA}

An ideal recombinant bacterial strain for deliberate field release would differ from the parent only in the new genes relevant to its new environmental function. For example, a bacterium designed for bioremediation of toluene-contaminated soil, would ideally contain only the additional toluene degradation genes. In particular, it would not contain unnecessary antibiotic resistance genes or remnants of the plasmids or transposons used to construct it.

An early attempt to make vector-free recombinant bacteria used homologous recombination into the recA gene of $S$. meliloti followed by a selection in sucrosecontaining medium to select for excision of plasmid sequences associated with the $s a c B$ gene present on the vector (Dammann-Kalinowski et al., 1996). Thus the only foreign DNA present in the resulting recombinant was the luc gene of Photinus pyralis attached to the Tn5 neomycin phosphotransferase promoter.

Advances in site-specific recombination systems have enabled cis-acting site-specific recombination sites to be incorporated into recombinant constructs. When two of these are inserted in the recombinant molecule, the intervening region may be subsequently deleted by transient expression of the site-specific recombination enzyme. The first demonstration of the power of sitespecific recombination technology used the Cre recombinase of phage $\mathrm{P} 1$ that acts at sites called loxP. Insertion of two loxP sites into the large RK2 broad-hostrange plasmid permitted site-specific deletion of the $\operatorname{trf} A$ gene, thereby showing it to be essential for RK2 DNA replication in all bacteria tested (Ayres et al., 1993).

More recently, other groups have used different sitespecific recombination methods to eliminate regions of DNA contained within a transposon integrated into the chromosome. The parA gene of the multimer resolution system of RP4 codes for a site-specific recombinase able to catalyze the separation (resolution) of RP4 plasmid dimers by acting at the res sites. The res sites were incorporated into a kanamycin resistant transposon, carrying $\operatorname{lu} x A B$ as a bioluminescent marker, in such a way that they were located on either side of the $K m^{R}$ gene. The transposon was then transposed to the chromosome of $P$. putida as shown in Figure 1. The resolvase was then transiently expressed, following transfer of a nonreplicative plasmid carrying the parA gene, and this resulted in site-specific deletion of the $\mathrm{Km}^{R}$ gene but not the lux genes (Kristensen et al., 1995). This method is shown diagrammatically in Figure 2. More recently this method has been used to construct a quasi-natural toluene degrading strain that contains no heterologous DNA other than that for toluene degradation. In this strain, toluene is initially degraded to benzoate by the enzymes of the TOL upper pathway and then degraded to Krebs 


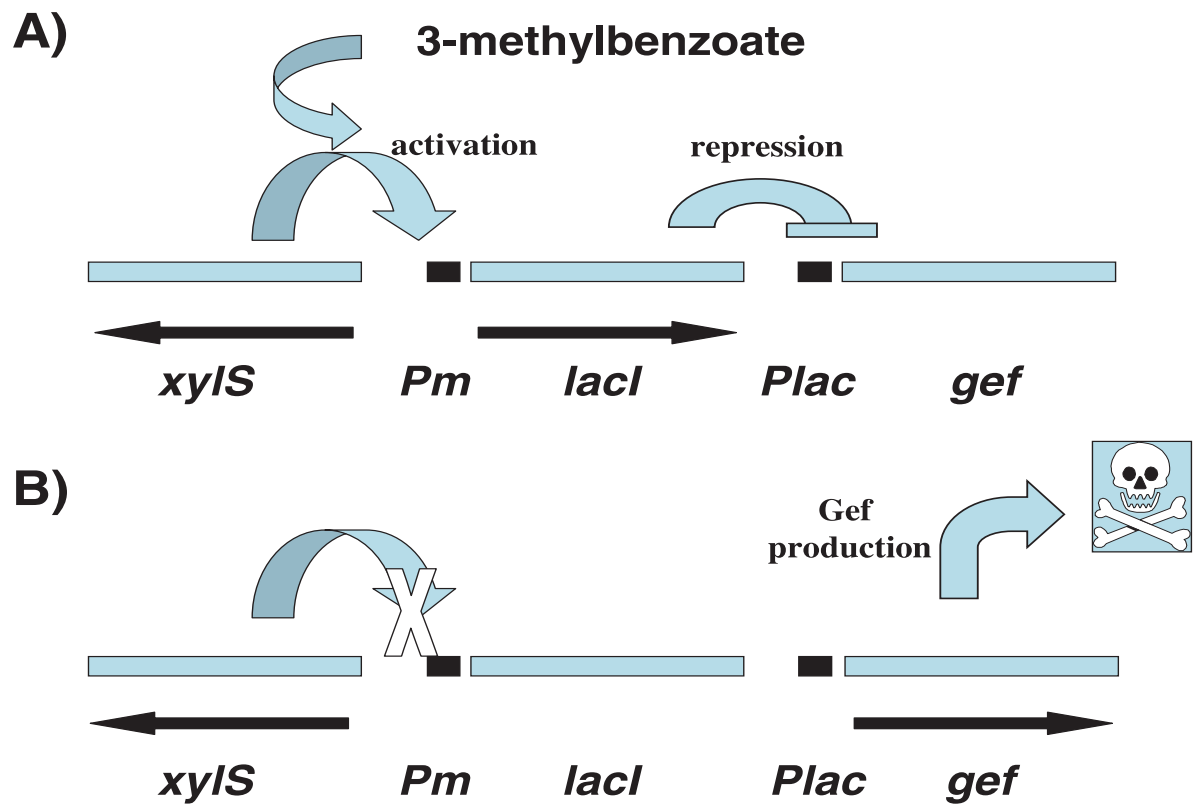

Figure 3. Substrate dependent cell suicide.

(A) A mini-transposon carries a series of genes forming a regulatory cascade. In the presence of the inducer 3-methylbenzoate, the XylS transcriptional activator is active on promoter Pm, permitting the production of the LacI repressor which then represses the lethal gef gene.

(B) However, when 3-methybenzoate is absent, the lacI gene is not transcribed so that the lethal Gef protein is produced resulting in cell death.

cycle intermediates by the host chromosomal orthodegradation pathway (Panke et al., 1998).

A similar method exploited the site-specific FLP recombinase of the Saccharomyces cerevisiae $2 \mu$ plasmid, which acts at the FRT sites (Cherepanov and Wackernagel, 1995). As with the parA/res system, the yeast recombinase could be used to remove antibiotic (or other) genes integrated into the $E$. coli chromosome. This system was improved upon and extended to $P$. aeruginosa so that unmarked recombinant strains could be isolated (Hoang et al., 1998; Hoang et al., 2000). These systems have been used to construct unmarked Pseudomonads carrying $g f p$ and lac $Z$ fusions for detection in environmental release experiments.

\section{CONDITIONAL LETHALITY SYSTEMS}

Several systems have been designed whereby the released recombinant bacterium has a built-in suicide system designed to be triggered by environmental circumstances (Molin et al., 1993; Ramos et al., 1994; Diaz et al., 1994; Munthali et al., 1996; Davison, 2001). In one scenario, a bacterium designed to degrade a particular environmental pollutant could be made to self-destruct once it had finished its job and the pollutant no longer remained in the environment. This would remove the problem of the long-term fate of the recombinant bacterium. In another scenario, it may be desirable that the recombinant bacterium survives in the environment but does not horizontally transfer its recombinant genes to other bacteria co-inhabiting the same environment.

Different suicide systems, with quite different mechanisms of action, have been demonstrated, though few have been extensively developed or investigated for their efficiency across a wide range of bacteria. The gef gene product of $E$. coli is a porin-inducing protein and kills many different types of bacteria by generating pores in the cell membrane, thereby destroying the membrane potential (Molin et al., 1993; Jensen and Gerdes, 1995). The relF gene of E. coli (Knudsen et al., 1995), the Hok protein of plasmid R1 (Bej et al., 1992), the $E$ gene protein of $\Phi \times 174$ (Ronchel et al., 1998), and the $\lambda S$ gene holin (Wang et al., 2000) have similar deleterious effects on the membrane. Expression of the nuclease of Serratia marcescens (Ahrenholtz et al., 1994), or the EcoRI restriction endonuclease (Torres et al., 2000), leads to intracellular degradation of the DNA and has been used 


\section{J. Davison}

to cause cell suicide and to prevent horizontal transfer. The bacterial toxin colicin E3 acts by site-specific cleavage of the $16 \mathrm{~S}$ ribosomal RNA and is lethal to many different bacteria (Diaz et al., 1994). Finally, the expression of streptavidin results in deprivation of biotin, an essential vitamin for cell growth (Szafranski et al., 1997). Most of these systems have been tested in $P$. putida, which is generally agreed to be a suitable model system for environmental release (Ramos et al., 2000).

A system has been elaborated whereby a recombinant P. putida, designed to degrade 3-methylbenzoate, would self-destruct once the pollutant was completely degraded. The lacI repressor gene was placed under control of the $P m$ promoter, which is itself positively controlled by the XylS regulator (Fig. 3). Under these conditions, the presence of 3-methylbenzoate caused activation of XylS resulting in synthesis of the LacI repressor which in turn represses the lac promoter controlling the synthesis of the lethal Gef protein (Molin et al., 1993; Jensen et al. 1993). Eliminating of the pollutant from the medium led to loss of LacI repression and induction of cell suicide by Gef synthesis. Escape from the killing effect of 3methylbenzoate deprivation was of the order of $10^{-8}$ per cell per generation (Molina et al., 1998). In contrast to the situation in E. coli and $P$. putida, the gef suicide system seemed to have much less toxicity for $P$. aeruginosa (Soberon-Chavez, 1996). A parallel system, with similar results, used the $E$ gene of phage $\Phi \times 174$ instead of gef (Ronchel et al., 1998).

The $P$. putida methylbenzoate-dependent killing system was further tested in outdoor soil assays. In unplanted soil, the numbers of both the contained strain and the uncontained control strain decreased with time, though the contained strain decreased faster than the control and faster in the absence of added methyl benzoate than in its presence. Under all conditions the contained strain died more easily than the control and this may reflect the reduced availability of methylbenzoate even in supplemented soils. The decrease in cell numbers was more dramatic in spring and summer than in autumn and winter. In planted soil the control strain became established at $10^{5}-10^{6} \mathrm{CFU}_{\mathrm{g}}{ }^{-1}$, regardless of the presence of methyl benzoate, but at much lower levels in bulk soil. The contained strain tended to disappear from the soil though at a faster a rate in the absence of methylbenzoate. Again, this rate of disappearance was faster in summer than in winter. No evidence was found for dispersal outside of the test site.

In E. coli, a different regulated promoter (fimA) was used to control gef expression (Klemm et al., 1995). The fimA promoter is located on an invertible DNA fragment and is active only in one orientation. The inversion switch is stochastic (time dependent) so that gef fusions were viable in one direction and lethal in the opposite direction. In actively growing cultures the presence of the fimA-gef fusion had little effect. However, in stationary phase cultures, viability rapidly dropped as the bacteria switched stochastically to the lethal expression phase. It was suggested that such bacteria would be suitable for contained industrial fermentations as a way to contain accidental release or accidental human infection.

One problem with suicide systems is that there may be spontaneous mutation of the lethal gene followed by selection of the mutants that may grow more quickly. Given the numbers of bacteria that would be potentially involved in a genuine field release experiment, the number of spontaneous mutants may not be negligible. Recently an improved double containment system has been devised whereby the XylS product controls the production not only the LacI repressor (that represses gef as above), but also of the asd gene protein which is essential for the production of diaminopimelic acid, an essential component of bacterial cell walls (Ronchel and Ramos, 2001). In this system, the host bacterium has a deletion for the asd region, so that cell survival depends on the presence of 3-methylbenzoate in the medium. Since diaminopimelic acid is not present in soil, elimination of the 3-methylbenzoate pollutant results in cell death for two independent reasons; Gef protein mediated membrane permeability and cell lysis due to diaminopimelic acid deprivation. The level of survival was below the limit of detection $\left(<10^{-9}\right.$ per cell per generation). In soil, it was found that the double contained gef-asd recombinant bacterium disappeared much more quickly than the simple gef contained recombinant, following 3-methylbenzoate deprivation.

A quite different suicide system takes advantage of the fact that bacterial cells have an absolute need for biotin (either synthesized within the cell or provided from the exterior). Streptavidin, a protein coded by the stv gene of Streptomyces avidini, has a great affinity for biotin and binds it quantitatively and almost irreversibly. It was found that production of streptavidin resulted in biotin deprivation and was lethal to $P$. putida. In direct analogy to the above experiments using the gef gene product, it was necessary to tightly control expression of the $s t v$ gene using the same 3-methybenzoate XylS/Pm gene control system. Thus, the recombinant bacteria died of biotin deprivation when deprived of 3-methylbenzoate (Szafranski et al., 1997). To avoid leakiness of the regulatory system, and unintentional cell death, it was necessary to install additional fail-safe mechanisms 
involving T7 RNA polymerase and T7 lysozyme, which regulates the activity of the $\mathrm{T} 7$ polymerase. For still more stringency, an additional regulation by an antisense RNA was also installed. This system showed cell survival at frequencies of $10^{-7}-10^{-8}$, depending on experimental conditions. A transposon variant has similarly been created. Combination of the streptavidin-induced lethality with other conditional lethality systems should result in highly efficient biocontained bacteria.

As explained above, horizontal transfer from the recombinant bacteria to neighboring bacteria in the ecosystem could be a serious concern for experiments involving the deliberate release of recombinant microorganisms. Two similar systems have used suicide functions to attempt to negate or reduce horizontal transfer. In one experiment, two plasmid borne relF genes of E. coli, (which codes for a protein belonging to the Gef family of functionally and structurally equivalent, toxic proteins) were placed under control of a chromosomally encoded LacI repressor. In this case, transfer of the plasmid to a heterologous bacterium would relieve LacI repression and activate Gef production resulting in cell death (Knudsen et al., 1995). The effectiveness of this system was tested in the rat intestine, where no transconjugants were detected in the contained bacteria; compared to $10^{2}-10^{3} \mathrm{~g}^{-1}$ of faeces in the controls. Suicide experiments (induced by IPTG) in sterile soil and sea water showed that a suicide level of $10^{-7}$ could be obtained. This level is consistent with the presence of a double relF gene on the plasmid so as to reduce mutational inactivation of the lethal function.

A conceptually similar, but functionally different, system used the protein antibiotic colicin E3, which acts by site-specific cleavage of the $16 \mathrm{~S}$ ribosomal RNA and is toxic to a wide variety of bacteria. In the normal in vivo situation, the toxic action of colicin E3 is counteracted by production of an immunity protein that binds to the RNase domain of the toxin. In a construction designed to prevent horizontal plasmid transfer, the colE3 gene was placed on a broad-host range plasmid and the imm gene on the bacterial chromosome. Thus, when plasmid transfer takes place, by transformation or conjugation, the colicin E3 toxin is produced in the absence of the immunity protein leading to death in the recipient. Reduced conjugation frequencies of $10^{-4}-10^{-5}$ were observed in a variety of bacteria including $R$. meliloti, Agrobacterium tumefaciens, Comamonas acidovorans, Alcaligenes eutrophus and P. fluorescens (Diaz et al., 1994). The same colicin E3 system was later applied to transposon systems, designed for the degradation of polychlorinated biphenyls. In this case the colE3 gene and the biphenyl degradation locus (bph) are closely linked so that chromosomal transfer, by conjugation, transduction or transformation, would result in their cotransfer to the recipient bacterium. The immunity (imm) locus is also located on the chromosome but at a distant locus so that it would not usually be co-transferred to the recipient bacterium. Thus, bacteria that receive the biodegradation locus would also receive the colicin E3 killing function, but not the imm locus, resulting in the death of the recipient (Munthali et al., 1996).

In terms of future developments, enough is now known about the molecular genetics of degradation in Pseudomonads that these conditional lethality systems could be adapted to other pollutants. However there may be other uses that have not yet been adequately explored. Laboratories handling plant, animal and human pathogens are subjected to draconian rules regarding physical containment. One could propose a new logic whereby these pathogens could first be subjected to genetic modification (for example using the XylS/Gef system) to reduce their pathogenicity. Thus, for example, such pathogens as Salmonella typhi or Yersinia pestis could first be disabled so that they could only grow in the presence of 3-methylbenzoate. By analogy to the $P$. putida experiments, this could reduce viability by more than $10^{-7}$ in the absence of 3-methylbenzoate (a figure that would compare most favorably with most kinds of physical containment). Again by analogy to the $P$. putida experiments, the system could be further improved by using two independent bio-containment functions. Naturally, some investigations with pathogens obligatorily require the natural pathogen with full pathogenic potential. However, probably more than of $90 \%$ are concerned with basic molecular biology and could better use a safer disabled strain. This type of idea would probably come up against regulations controlling the construction of genetically modified organisms. The genetic modification of a pathogen, even to make it several orders of magnitude safer, would probably require greater containment facilities than those for handling the original disease-forming parent.

\section{DISCUSSION AND CONCLUSIONS}

This review presents recent progress towards the construction of recombinant bacteria designed for free release into the environment. These systems have evolved considerable over recent years and several important research trends are apparent:

(1) There is a tendency to move away from plasmid vectors towards chromosomally integrated defective 


\section{J. Davison}

transposon vectors. This simultaneously increases the stability of the recombinant construct, particularly in the absence of genetic selection, and reduces the possibility of horizontal transfer to other bacteria found in the environment.

(2) There is a tendency to choose selective markers other than those coding for antibiotic resistance. In particular, resistance to nickel seems to work well in a variety of members of the $\alpha, \beta$, and $\gamma$ subclasses of the Proteobacteria. Resistance to tellurite also seems promising. It should be remembered that such selective markers are needed only for the initial recombinant construction in the laboratory and should provide neither a positive nor negative selection under normal field conditions.

(3) New site-specific recombination methods enable the construction of "pseudo-wild-type" bacteria that contain no unnecessary genetic material and differ from the parent only in the few genes that are relevant to the field trial experiment.

(4) A number of suicide systems enable the contained release of recombinant bacteria. Certain combinations of these of these allow the conditional killing of by up to eight orders of magnitude. The best model situation is designed for pollution clean-up by $P$. putida, and uses the 3-methylbenzoate responsive XylS regulatory protein to control lethal functions. Thus, the depolluting bacteria would die when the relevant pollutant was exhausted from the environment.

(5) Suicide systems may also serve to prevent the horizontal transfer of recombinant genetic information from the bacteria deliberately released into the environment to other bacteria with which they may come into contact.

\section{ACKNOWLEDGMENTS}

This work was supported by a contract (GMO RES COM, QLAM-2001-00037) from the European Community Quality of Life, 5th Framework Programme.

Received September 4, 2001; accepted June 7, 2002.

\section{REFERENCES}

Ahrenholtz I, Lorenz MG, Wackernagel W (1994) A conditional suicide system in Escherichia coli based on the intracellular degradation of DNA. Appl. Environ. Microbiol. 60: $3746-3751$

Ayres EK, Thomson VJ, Merino G, Balderes D, Figurski

DH (1993) Precise deletions in large bacterial genomes by vector-mediated excision (VEX). The trfA gene of promiscuous plasmid RK2 is essential for replication in several Gram-negative hosts. J. Mol. Biol. 230: 174-185

Barbosa TM, Levy SB (2000) The impact of antibiotic use on resistance development and persistence. Drug Resist. Updat. 3: 303-311

Bej AK, Molin S, Perlin M, Atlas RM (1992) Maintenance and killing efficiency of conditional lethal constructs in Pseudomonas putida. J. Ind. Microbiol. 10: 79-85

Bumann D, Hueck C, Aebischer T, Meyer TF (2000) Recombinant live Salmonella spp. for human vaccination against heterologous pathogens. FEMS Immunol. Med. Microbiol. 27: 357-364

Cherepanov PP, Wackernagel W (1995) Gene disruption in Escherichia coli: $\mathrm{TcR}$ and $\mathrm{KmR}$ cassettes with the option of Flp-catalyzed excision of the antibiotic-resistance determinant. Gene 158: 9-14

Dammann-Kalinowski T, Niemann S, Keller M, Selbitschka W, Tebbe CC, Puihler A (1996) Characterization of two bioluminescent Rhizobium meliloti strains constructed for field releases. Appl. Microbiol. Biotechnol. 45: 509-512

Davies JE (1997) Origins, acquisition and dissemination of antibiotic resistance determinants. Ciba Found Symp. 207: $15-27$

Davison J (1999) Genetic exchange between bacteria in the environment. Plasmid 42: 73-91

Davison J. (2002) Genetic Tools for Pseudomonads, Rhizobia and other Gram-negative Bacteria: a Review. Biotechniques 32: 386-401

Davison J, Brunel F, Kone K, Chevalier N (1990) Recombinant DNA Vectors for Pseudomonas. In: Silver S, Chakrabarty AM, Iglewski B, Kaplan S, eds, Pseudomonas, Biotransformations, Pathogenesis and Evolving Biotechnology. American Society for Microbiology, pp 242-251

de Lorenzo V (1994) Designing microbial systems for gene expression in the field. Trends Biotechnol. 12: 365-371

de Lorenzo V, Timmis KN (1994) Analysis and construction of stable phenotypes in gram-negative bacteria with $T n 5$ - and Tn10-derived minitransposons. Methods Enzymol. 235: 386405

de Lorenzo V, Herrero M, Jakubzik U, Timmis KN (1990) Mini-Tn5 transposon derivatives for insertion mutagenesis, promoter probing, and chromosomal insertion of cloned DNA in Gram-negative eubacteria. J. Bacteriol. 172: 6568-6572

de Lorenzo V, Herrero M, Sanchez JM, Timmis KN (1998) Mini-transposons in microbial ecology and environmental biotechnology. FEMS Microbiol. Ecol. 27: 211-224

Diaz E, Munthali M, de Lorenzo V, Timmis KN (1994) Universal barrier to lateral spread of specific genes among microorganisms. Mol. Microbiol. 13: 855-861

Govan JR, Hughes JE, Vandamme P (1996) Burkholderia cepacia: medical, taxonomic and ecological issues. J. Med. Microbiol. 45: 395-407

Haas D, Blumer C, Keel C (2000) Biocontrol ability of fluorescent pseudomonads genetically dissected: importance 
of positive feedback regulation. Curr. Opin. Biotechnol. 11: 290-297

Hansen LH, Sorensen SJ, Jensen LB (1997) Chromosomal insertion of the entire Escherichia coli lactose operon, into two strains of Pseudomonas, using a modified mini-Tn5 delivery system. Gene 186: 167-173

Herrero M, de Lorenzo V, Timmis KN (1990) Transposon vectors containing non-antibiotic resistance selection markers for cloning and stable chromosomal insertion of foreign genes in Gram-negative bacteria. J. Bacteriol. 172: 6557-6567

Hoang TT, Karkhoff-Schweizer RR, Kutchma AJ, Schweizer HP (1998) A broad-host-range Flp-FRT recombination system for site-specific excision of chromosomally-located DNA sequences: application for isolation of unmarked Pseudomonas aeruginosa mutants. Gene 212: 77-86

Hoang TT, Kutchma AJ, Becher A, Schweizer HP (2000) Integration-proficient plasmids for Pseudomonas aeruginosa: site-specific integration and use for engineering of reporter and expression strains. Plasmid 43: 59-72

Holmes A, Govan J, Goldstein R (1998) Agricultural use of Burkholderia (Pseudomonas) cepacia: a threat to human health? Emerg. Infect. Dis. 4: 221-227

Hooton TM, Levy SB (2001) Antimicrobial resistance: a plan of action for community practice. Am. Fam. Physician 63: 1087-1098

Jensen LB, Ramos JL, Kaneva Z, Molin S (1993) A substrate-dependent biological containment system for Pseudomonas putida based on the Escherichia coli gef gene. Appl. Environ. Microbiol. 59: 3713-3717

Jensen RB, Gerdes K (1995) Programmed cell death in bacteria: proteic plasmid stabilization systems. Mol. Microbiol. 17: 205-210

Kaniga K, Davison J (1991) Transposon vectors for stable chromosomal integration of cloned genes in rhizosphere bacteria. Gene 100: 201-205

Kappeli O, Auberson L (1997) The science and intricacy of environmental safety evaluations. Trends Biotechnol. 15: 342-349

Klemm P, Jensen LB, Molin S (1995) A stochastic killing system for biological containment of Escherichia coli. Appl. Environ. Microbiol. 61: 481-486

Knudsen S, Saadbye P, Hansen LH, Collier A, Jacobsen BL, Schlundt J, Karlstrom OH (1995) Development and testing of improved suicide functions for biological containment of bacteria. Appl. Environ. Microbiol. 61: 985-991

Kok M, Rekik M, Witholt B, Harayama S (1994) Conversion of pBR322-based plasmids into broad-host-range vectors by using the Tn3 transposition mechanism. J. Bacteriol. 176: 6566-6571

Kristensen CS, Eberl L, Sanchez-Romero JM, Givskov M, Molin S, de Lorenzo V (1995) Site-specific deletions of chromosomally located DNA segments with the multimer resolution system of broad-host-range plasmid RP4. $J$. Bacteriol. 177: 52-58
Matic I, Taddei F, Radman M (1996) Genetic barriers among bacteria. Trends Microbiol. 4: 69-72

Miller H (1997) The EPA's war on bioremediation. Nat. Biotechnol. 15: 486

Molin S, Boe L, Jensen LB, Kristensen CS, Givskov M, Ramos JL, Bej AK (1993) Suicidal genetic elements and their use in biological containment of bacteria. Annu. Rev. Microbiol. 47: 139-166

Molina L, Ramos C, Ronchel MC, Molin S, Ramos JL (1998) Construction of an efficient biologically contained Pseudomonas putida strain and its survival in outdoor assays. Appl. Environ. Microbiol. 64: 2072-2078

Munthali M, Timmis KN, Diaz E (1996) Restricting the dispersal of recombinant DNA: Design of a contained biological catalyst. Biotechnology (NY) 14: 189-191

Panke S, Sanchez-Romero JM, de Lorenzo V (1998) Engineering of quasi-natural Pseudomonas putida strains for toluene metabolism through an ortho-cleavage degradation pathway. Appl. Environ. Microbiol. 64: 748-751

Pieper DH, Reineke W (2000) Engineering bacteria for bioremediation. Curr. Opin. Biotechnol. 11: 262-270

Raaijmakers JM, Bitter W, Punte HL, Bakker PA, Weisbeek PJ, Schippers B (1994) Siderophore receptor PupA as a marker to monitor wild-type Pseudomonas putida WCS358 in natural environments. Appl. Environ. Microbiol. 60: $1184-1190$

Ramos C, Molina L, Molbak L, Ramos JL, Molin S (2000) A bioluminescent derivative of Pseudomonas putida KT2440 for deliberate release into the environment. FEMS Microbiol. Ecol. 34: 91-102

Ramos JL, Diaz E, Dowling D, de Lorenzo V, Molin S, O'Gara F, Ramos C, Timmis KN (1994) The behavior of bacteria designed for biodegradation. Biotechnology (NY) 12 : 1349-1356

Ronchel MC, Molina L, Witte A, Lutbiz W, Molin S, Ramos JL, Ramos C (1998) Characterization of cell lysis in Pseudomonas putida induced upon expression of heterologous killing genes. Appl. Environ. Microbiol. 64: 4904-4911

Ronchel MC, Ramos JL (2001) Dual system to reinforce biological containment of recombinant bacteria designed for rhizoremediation. Appl. Environ. Microbiol. 67: 2649-2656

Saint CP, Alexander S, McClure NC (1995) pTIM3, a plasmid delivery vector for a transposon-based inducible marker gene system in Gram-negative bacteria. Plasmid, 34: 165-174

Sanchez-Romero JM, Diaz-Orejas R, de Lorenzo V (1998) Resistance to tellurite as a selection marker for genetic manipulations of Pseudomonas strains. Appl. Environ. Microbiol. 64: 4040-4046

Sayler GS, Ripp S (2000) Field applications of genetically engineered microorganisms for bioremediation processes. Curr. Opin. Biotechnol. 11: 286-289

Soberon-Chavez G (1996) Evaluation of the biological containment system based on the Escherichia coli gef gene in 


\section{J. Davison}

Pseudomonas aeruginosa W51D. Appl. Microbiol. Biotechnol. 46: 549-553

Szafranski P, Mello CM, Sano T, Smith CL, Kaplan DL, Cantor CR (1997) A new approach for containment of microorganisms: dual control of streptavidin expression by antisense RNA and the T7 transcription system. Proc. Natl. Acad. Sci. USA 94: 1059-1063

Taghavi S, Delanghe H, Lodewyckx C, Mergeay M, Der Lelie DD (2001) Nickel-resistance-based minitransposons: new tools for genetic manipulation of environmental bacteria. Appl. Environ. Microbiol. 67: 1015-1019

Top E, Mergeay M, Springael D, Verstraete W (1990) Gene escape model: transfer of heavy metal resistance genes from Escherichia coli to Alcaligenes eutrophus on agar plates and in soil samples. Appl. Environ. Microbiol. 56: 2471-2479

Torres B, Jaenecke S, Timmis KN, Garcia JL, Diaz E (2000) A gene containment strategy based on a restrictionmodification system. Environ. Microbiol. 2: 555-563

Wang IN, Smith DL, Young R (2000) Holins: the protein clocks of bacteriophage infections. Annu. Rev. Microbiol. 54: 799-825

Zuo J, Niu QW, Ikeda Y, Chua NH (2002) Marker-free transformation: increasing transformation frequency by the use of regeneration-promoting genes. Curr. Opin. Biotechnol. 13: 173-180

To access this journal online: www.edpsciences.org 